\title{
Effect of long-term water immersion or thermal shock on mechanical properties of high-impact acrylic denture base resins
}

\author{
Hirono SASAKI, Ippei HAMANAKA, Yutaka TAKAHASHI and Tomohiro KAWAGUCHI \\ Division of Removable Prosthodontics, Fukuoka Dental College, 2-15-1 Tamura, Sawara-ku, Fukuoka 814-0193, Japan \\ Corresponding author, Yutaka TAKAHASHI; E-mail: ytakaha@college.fdcnet.ac.jp
}

\begin{abstract}
The purpose of this study was to investigate the effect of long-term water immersion or thermal shock on the mechanical properties of high-impact acrylic denture base resins. Two high-impact acrylic denture base resins were selected for the study. Specimens of each denture base material tested were fabricated according to the manufacturers' instructions $(n=10)$. The flexural strength at the proportional limit, the elastic modulus and the impact strength of the specimens were evaluated. The flexural strength at the proportional limit of the high-impact acrylic denture base resins did not change after six months' water immersion or thermocycling 50,000 times. The elastic moduli of the high-impact acrylic denture base resins significantly increased after six months' water immersion or thermocycling 50,000 times. The impact strengths of the high-impact acrylic denture base resins significantly decreased after water immersion or thermocycling as described above.
\end{abstract}

Keywords: Elastic modulus, Flexural property, Flexural strength at proportional limit, Impact strength, Thermocycling

\section{INTRODUCTION}

Characterizing the failure record of removable dentures, Hargreaves $^{1)}$ found that $68 \%$ of dentures had broken by the end of three years after placement, and YliUrpo et $a l .^{2)}$ reported that $28 \%$ of dentures underwent repair during the first year of use and 39\% required repair during the first three years of use. Fracture of acrylic resin removable dentures occurs both outside and inside the mouth. Failure occurs outside the mouth through impact as a result of dropping the denture, and excessive biting force causes fracture inside the mouth $^{3)}$. For maxillary dentures, most fractures are caused by a combination of fatigue and impact, whereas for mandibular dentures, $80 \%$ of fractures are caused by impact ${ }^{4}$.

High-impact denture base resins have been introduced, and these materials are supplied in a powder-liquid form and are processed in the same way as other heat-polymerized methyl methacrylate resins. These polymers are reinforced with butadiene-styrene rubber and the rubber particles are grafted to methyl methacrylate to bond to the acrylic matrix ${ }^{5}$. Highimpact denture base resins have been investigated ${ }^{6-11}$. The ultimate flexural strength ${ }^{8,9,11)}$, elastic modulus ${ }^{6,8,9)}$ and impact strength ${ }^{6,8-11)}$ of these high-impact denture base resins were studied. Their dimensional stability ${ }^{7}$ was also examined. Removable denture base resins typically exhibit considerable plastic deformation before fracture. The plastic deformation beyond its proportional limit permanently alters the dimensions of a removable denture, and it is not clinically acceptable; therefore, some studies evaluated the resistance of denture base resins to plastic deformation under a flexural load ${ }^{12-16)}$. Despite, the flexural strength at the proportional limit of high-impact denture base resin has not been quantified.

A removable acrylic resin denture is subjected to a multitude of conditions intraorally that could alter its dimensions or structural integrity. The moist intraoral environment obviously facilitates water sorption into the denture base resin. Poly (methyl methacrylate) absorbs relatively small amounts of water when placed in an aqueous environment, but this water exerts significant effects on the mechanical and dimensional properties of the polymer ${ }^{17)}$. Water molecules penetrate the poly(methyl methacrylate) mass and occupy spaces between the polymer chains, forcing the affected chains apart. The introduction of water molecules into the polymerized mass produces two important effects: first, it causes a slight expansion of the polymerized mass, and second, the water molecules interfere with the entanglement of the polymer chains, thereby acting as plasticizers ${ }^{17)}$. Hence, estimation of the effect of longterm water immersion on the mechanical properties of high-impact denture base resins is beneficial for clinical purposes; however, it has not yet been investigated until now.

Denture resins are routinely subjected to thermal stress in the oral cavity, especially during the ingestion of hot and cold food and beverages ${ }^{11}$. It is preferable for high-impact denture base resins to maintain impact resistance. Thus, evaluation of the effect of thermal shock on the mechanical properties of high-impact denture base resins is of significant clinical value. A previous study investigated the ultimate flexural and impact strengths of a high-impact acrylic denture base resin after thermocycling 5,000 times ${ }^{11)}$; however, there is little information to evaluate the effect of thermal shock on the mechanical properties of high-impact acrylic denture base resins.

It is probable that long-term water immersion and 
thermal shock affect the mechanical properties of highimpact acrylic denture base resins. It was hypothesized that long-term water immersion or thermal shock would affect the mechanical properties of these resins. The purpose of this study was to investigate the effect of long-term water immersion or thermal shock on the mechanical properties of high-impact acrylic denture base resins.

\section{MATERIALS AND METHODS}

Two high-impact acrylic denture base resins were selected for the study, and a conventional acrylic denture base resin was used as a control (Table 1).

The flexural properties and Charpy impact strength of the denture base materials were measured according to ISO $1567^{18)}$ and ISO 1567: 1999/Amd 1: $2003^{19)}$.

\section{Flexural properties}

The specimens of each denture base resin tested were fabricated according to the manufacturers' instructions in gypsum molds with cavities $(65 \mathrm{~mm}$ long $\times 10 \mathrm{~mm}$ wide $\times 3.3 \mathrm{~mm}$ high). Each specimen was polished with 600-grit SiC paper. The accuracy of the dimensions was verified with a vernier micrometer (KSM15FF, NAKAMURA MFG, Tokyo, Japan) at three locations for each dimension to within a $0.05-\mathrm{mm}$ tolerance for width and height. The specimens of each denture base resin were divided into three groups. Before testing, one group was stored in $37^{\circ} \mathrm{C}$ distilled water for $50 \mathrm{~h}$, another group was stored in $37^{\circ} \mathrm{C}$ distilled water for 180 days, and the third group was thermocycled between 5 and $55^{\circ} \mathrm{C}$ water in 1-min cycles for 50,000 cycles. Ten specimens were fabricated per group.
The flexural strength at the proportional limit ${ }^{12-16)}$ and the elastic modulus of the specimens were tested. Each specimen was placed on a $50 \mathrm{~mm}$-long support for three-point flexural testing. A vertical load was applied at the midpoint of the specimen at a crosshead speed of $5 \mathrm{~mm} / \mathrm{min}$ on a load testing machine (ASG-J, Shimadzu, Kyoto, Japan).

The flexural strength at the proportional limit (MPa) was calculated according to the following formula:

flexural strength at the proportional limit $=3 \mathrm{~F}_{1} 1 / 2 \mathrm{bh}^{2}$

where $\mathrm{F}_{1}=$ the load $(\mathrm{N})$ at the proportional limit, $\mathrm{l}=$ the span distance $(50 \mathrm{~mm}), \mathrm{b}=$ the width $(\mathrm{mm})$ of the specimen, and $\mathrm{h}=$ the height $(\mathrm{mm})$ of the specimen. The load at the proportional limit was determined from each load/deflection graph.

The elastic modulus (GPa) was calculated using the following formula:

Elastic modulus $=\mathrm{F}_{2} \mathrm{l}^{3 / 4} \mathrm{bh}^{3} \mathrm{~d}$

where $\mathrm{F}_{2}=$ the load $(\mathrm{N})$ at a point in the straight line portion of the load/deflection graph, and $\mathrm{d}=$ the deflection (mm) at load $\mathrm{F}_{2}$.

\section{Charpy impact test}

Specimens of each denture base material were fabricated according to the manufacturers' instructions in gypsum molds with cavities $50 \mathrm{~mm}$ long $\times 6 \mathrm{~mm}$ wide $\times 4 \mathrm{~mm}$ high . Each specimen was polished with 600-grit SiC paper, and the accuracy of the dimensions was verified with a micrometer to within a $0.2-\mathrm{mm}$ tolerance for the width and height at three locations for each dimension. A

Table 1 Denture base resins tested in this study

\begin{tabular}{|c|c|c|c|c|c|c|}
\hline $\begin{array}{c}\text { Denture } \\
\text { base resin }\end{array}$ & Manufacturer & Description & $\begin{array}{l}\text { Processing } \\
\text { method }\end{array}$ & $\begin{array}{c}\text { Powder } \\
\text { constituent(s) }\end{array}$ & $\begin{array}{c}\text { Liquid } \\
\text { constituent(s) }\end{array}$ & $\begin{array}{l}\text { Lot number } \\
\text { (powder, liquid) }\end{array}$ \\
\hline ProImpact & $\begin{array}{l}\text { GC, Tokyo, } \\
\text { Japan }\end{array}$ & $\begin{array}{c}\text { Heat } \\
\text { polymerized, } \\
\text { high-impact }\end{array}$ & $\begin{array}{l}\text { Compression mold } \\
\text { technique; heat } \\
\text { processed at } 70^{\circ} \mathrm{C} \\
\text { for } 90 \mathrm{~min} \text {, then } \\
100^{\circ} \mathrm{C} \text { for } 30 \mathrm{~min}\end{array}$ & $\begin{array}{c}\text { PMMA } \\
\text { (with rubber } \\
\text { molecules) }\end{array}$ & MMA & $\begin{array}{l}\text { (P) } 1402042, \\
\text { (L)1312171 }\end{array}$ \\
\hline $\begin{array}{l}\text { Lucitone } \\
199\end{array}$ & $\begin{array}{c}\text { DENTSPLY } \\
\text { International, } \\
\text { PA, USA }\end{array}$ & $\begin{array}{c}\text { Heat } \\
\text { polymerized, } \\
\text { high-impact }\end{array}$ & $\begin{array}{l}\text { Compression mold } \\
\text { technique; heat } \\
\text { processed at } 70^{\circ} \mathrm{C} \\
\text { for } 90 \text { min, then } \\
100^{\circ} \mathrm{C} \text { for } 30 \text { min }\end{array}$ & $\begin{array}{c}\text { PMMA } \\
\text { (with rubber } \\
\text { molecules), } \\
\text { dibenzoyl peroxide } \\
(<0.2 \%), \text { titanium } \\
\text { dioxide }(<0.05 \%)\end{array}$ & $\begin{array}{l}\text { MMA, } \\
\text { EGDMA }\end{array}$ & $\begin{array}{l}\text { (P)140123, } \\
\text { (L)1401152 }\end{array}$ \\
\hline Acron & GC & $\begin{array}{c}\text { Heat } \\
\text { polymerized, } \\
\text { conventional }\end{array}$ & $\begin{array}{l}\text { Compression mold } \\
\text { technique; heat } \\
\text { processed at } 70^{\circ} \mathrm{C} \\
\text { for } 90 \mathrm{~min} \text {, then } \\
100^{\circ} \mathrm{C} \text { for } 30 \mathrm{~min}\end{array}$ & PMMA & MMA & $\begin{array}{l}\text { (P)1401211, } \\
\text { (L)1401291 }\end{array}$ \\
\hline
\end{tabular}

PMMA=poly(methyl methacrylate); MMA=methyl methacrylate; EGDMA=ethylene glycol dimethacrylate. 
notch (type A) was cut in the middle of each specimen, as described in ISO $179^{20)}$. An edgewise notch was cut to a depth of $1.2 \mathrm{~mm}$, leaving a residual depth of 4.8 $\mathrm{mm}$ beneath the notch. The specimens of each denture base resin were divided into three groups. Before testing, one group was stored in a container of water at $37^{\circ} \mathrm{C}$ for 7 days, another group was stored in $37^{\circ} \mathrm{C}$ distilled water for 180 days, and the third group was thermocycled between 5 and $55^{\circ} \mathrm{C}$ water in 1 -min cycles for 50,000 cycles. They were conditioned in the container at $23^{\circ} \mathrm{C}$ for $60 \mathrm{~min}$ prior to testing. Ten specimens were fabricated for each group.

A Charpy notched impact strength test was carried out on a pendulum impact tester (DC-C, Toyo Seiki, Tokyo, Japan). After conditioning, the specimen was removed from the water and placed on the specimen supports of the testing apparatus. The test span was $40 \mathrm{~mm}$. The specimen was placed with the notch facing away from the point of impact from the pendulum, and then the pendulum was released in order to fracture the specimen. The Charpy impact strength $\left(\mathrm{kJ} / \mathrm{m}^{2}\right)$ of the notched specimen was calculated using the formula:

$$
\text { Impact strength }=(\mathrm{J} 1-\mathrm{J} 2) \times 10^{3} / \mathrm{bh}
$$

where $\mathrm{J} 1=$ the value of energy absorbed by the specimen, J2=the friction energy of the system, $b=$ the depth behind the notch, and $\mathrm{h}=$ the height of the specimen.

All the tests were performed under uniform atmospheric conditions of $23.0 \pm 1^{\circ} \mathrm{C}$ and $50 \pm 1 \%$ relative humidity.

The Kolmogorov-Smirnov test (STATISTICA, StatSoft, Tulsa, OK, USA) was performed for each group to inquire into normal or non-normal of distribution $(p=0.05)$. One-way analysis of variance (ANOVA) (STATISTICA) was performed if all groups showed normal distribution $(p=0.05)$, and Newman-Keuls post $h o c$ comparison (STATISTICA) $(p=0.05)$ was applied when appropriate.

\section{RESULTS}

The Kolmogorov-Smirnov test revealed that all groups showed normal distribution. The one-way ANOVA revealed significant differences among denture base resins for each condition of the flexural strength at the proportional limit, the elastic modulus, and the Charpy impact strength $(p<0.05)$.

For the flexural strengths at the proportional limit, the 50-h water-immersed specimens of ProImpact and Lucitone199 were not significantly different $(p>0.05)$, and the 50-h water-immersed specimens of Lucitone 199 and Acron were not significantly different $(p>0.05)$. The flexural strengths at the proportional limit of ProImpact and Lucitone199 did not change after long-term water immersion or thermal shock $(p>0.05)$, and the strength of Acron significantly decreased after thermal shock $(p<0.05)$ (Table 2).

ProImpact and Lucitone199 had a significantly lower elastic modulus than Acron $(p<0.05)$, and the elastic moduli of all of denture base resins significantly increased after long-term water immersion or thermal shock. The descending order of the elastic modulus according to the denture base material, arranged in terms of statistical significance, was: Acron>Lucitone $199>$ ProImpact $(p<0.05)$ (Table 2$)$.

The descending order of the impact strength according to the denture base material, arranged by statistical significance, was: ProImpact $>$ Lucitone 199> Acron $(p<0.05)$. The impact strength of all of the denture base resins significantly decreased after long-term water immersion or thermal shock $(p<0.05)$ (Table 3$)$.

Table 2 Mean and standard deviation (SD) of the flexural properties of the denture base resins $(n=10)$.

\begin{tabular}{llcc}
\hline $\begin{array}{c}\text { Denture base } \\
\text { resin }\end{array}$ & \multicolumn{1}{c}{ Condition } & $\begin{array}{c}\text { Flexural strength at } \\
\text { proportional limit (MPa); } \\
\text { Mean (SD) }\end{array}$ & $\begin{array}{c}\text { Elastic modulus (GPa); } \\
\text { Mean (SD) }\end{array}$ \\
\hline ProImpact & 50 h water immersion & $29.0(2.3)^{* \mathrm{~b}, \mathrm{c}}$ & $2.15(0.06)$ \\
ProImpact & 180 days water immersion & $28.2(1.0)^{\mathrm{c}}$ & $2.26(0.04)^{\mathrm{a}}$ \\
ProImpact & 50,000 thermocycles & $27.8(1.8)^{\mathrm{c}}$ & $2.33(0.15)^{\mathrm{a}}$ \\
Lucitone 199 & 50 h water immersion & $32.2(2.3)^{\mathrm{a}, \mathrm{b}}$ & $2.37(0.14)^{\mathrm{a}}$ \\
Lucitone 199 & 180 days water immersion & $31.4(2.3)^{\mathrm{a}, \mathrm{b}, \mathrm{c}}$ & $2.73(0.07)$ \\
Lucitone 199 & 50,000 thermocycles & $28.8(2.1)^{\mathrm{b}, \mathrm{c}}$ & $2.54(0.07)$ \\
Acron & 50 h water immersion & $33.3(4.7)^{\mathrm{a}}$ & $2.96(0.17)$ \\
Acron & 180 days water immersion & $33.8(1.9)^{\mathrm{a}}$ & $3.08(0.04)$ \\
Acron & 50,000 thermocycles & $29.8(4.9)^{\mathrm{b}, \mathrm{c}}$ & $3.20(0.11)$ \\
\hline
\end{tabular}

${ }^{* a}$ or ${ }^{\mathrm{b}}$ or ${ }^{\mathrm{c}}$ denotes no significant differences among the denture base resin/condition combination $(p>0.05)$. 
Table 3 Mean and standard deviation (SD) of the Charpy impact strength of the denture base resins $(n=10)$.

\begin{tabular}{llc}
\hline Denture base resin & \multicolumn{1}{c}{ Condition } & Impact strength $\left(\mathrm{kJ} / \mathrm{m}^{2}\right) ; \mathrm{Mean}(\mathrm{SD})$ \\
\hline ProImpact & 7 days water immersion & $5.45(0.22)$ \\
ProImpact & 180 days water immersion & $4.95(0.07)$ \\
ProImpact & 50,000 thermocycles & $5.14(0.22)$ \\
Lucitone 199 & 7 days water immersion & $3.14(0.15)$ \\
Lucitone 199 & 180 days water immersion & $2.82(0.28)^{* \mathrm{a}}$ \\
Lucitone 199 & 50,000 thermocycles & $2.81(0.06)^{\mathrm{a}}$ \\
Acron & 7 days water immersion & $1.81(0.14)$ \\
Acron & 180 days water immersion & $1.45(0.21)^{\mathrm{b}}$ \\
Acron & 50,000 thermocycles & $1.28(0.35)^{\mathrm{b}}$ \\
\hline
\end{tabular}

${ }^{* a}$ or ${ }^{\mathrm{b}}$ denotes no significant differences among the denture base resin/condition combination $(p>0.05)$.

\section{DISCUSSION}

The hypothesis of this study was partially accepted, and long-term water immersion or thermal shock affected the elastic moduli and the impact strengths of highimpact acrylic denture base resins.

In this study, the flexural strength at the proportional limit was evaluated. In a previous study ${ }^{21)}$, long-term water immersion generally decreased the ultimate flexural strength of conventional denture base resins, but long-term water immersion generally did not change the flexural strength at the proportional limit of conventional denture base resins. Consequently, the tendency of the ultimate flexural strength of the denture base resins after six months' water immersion was somewhat different from that of the flexural strength at the proportional limit. The results seemed to indicate that the flexural strengths at the proportional limit of the conventional denture base resins generally tended not to change after long-term water immersion. In this study, the flexural strength at the proportional limit of the two high-impact acrylic denture base resins and the conventional acrylic denture base resin did not change significantly after six months' water immersion; these results were similar to the previous study testing conventional denture base resins after six months' water immersion ${ }^{21)}$. Thus, the flexural strength at the proportional limit of the high-impact acrylic denture base resin seemed not to change after long-term water immersion. Likewise, in this study, the flexural strength at the proportional limit of the two high-impact acrylic denture base resins did not change significantly after thermocycling 50,000 times between 5 and $55^{\circ} \mathrm{C}$ water in 1 -min cycles, but the flexural strength at the proportional limit of the conventional acrylic denture base resin significantly decreased after thermocycling. The result for the conventional acrylic denture base resin was similar to the previous study ${ }^{22)}$ of a conventional denture base resin after thermocycling 50,000 times. In another earlier study ${ }^{11)}$, the ultimate flexural strength of a highimpact acrylic denture base resin significantly decreased after thermocycling 5,000 times. The tendency of the ultimate flexural strength of the high-impact acrylic denture base resin after thermocycling was different from the present result for the flexural strength at the proportional limit of the high-impact acrylic denture base resin after thermocycling. Consequently, in this study, the result seemed to indicate that the flexural strengths at the proportional limit of the high-impact acrylic denture base resin tended not to change after thermocycling.

In this study, the elastic moduli of the two highimpact acrylic denture base resins and the conventional acrylic denture base resin significantly increased after six months' water immersion or after thermocycling. These results were similar to the results in other studies for the elastic moduli of conventional denture base resins after six months' water immersion ${ }^{21)}$ and for the elastic modulus of a conventional denture base resin after thermocycling 50,000 times ${ }^{22)}$. As the equilibrium water sorption is achieved in $24 \mathrm{~h}^{5)}$, the control specimen in the present study seemed to reach water sorption saturation after 50 hours' water immersion. As the denture base resin was immersed in water, soluble constituents such as unreacted monomers, plasticizers, and initiators leached out ${ }^{23)}$. The remaining microvoids formed were filled with water molecules through inward diffusion. Both the outward leakage of the soluble constituents and the inward diffusion of water were time-dependent processes. Hence, the relative amount of these molecules within the denture base resin changes over time until equilibrium is reached ${ }^{15)}$. Water, plasticizers, and unreacted monomers adversely affected the strength of the denture base resin to different extents because those molecules facilitate the movement of the polymer chains to varying degrees. Thus, the strength of a denture 
base resin at a given time after water immersion was affected by the relative number of those molecules present ${ }^{15)}$. Similarly, the outward leakage of the soluble constituents affected the mechanical properties in this study, and it seemed that the elastic modulus increased. Likewise, the elastic moduli of the two high-impact acrylic denture base resins and the conventional acrylic denture base resin significantly increased after thermocycling in this study. It seems that not only water sorption but also static fatigue caused by thermal stress affected the elastic moduli of the high-impact acrylic denture base resins and the conventional acrylic denture base resin. From these results, it appears that high-impact acrylic denture base resins tend to increase the elastic modulus after long-term water immersion or thermal shock.

The impact strength of the two high-impact acrylic denture base resins and the conventional acrylic denture base resin significantly decreased after six months' water immersion or 50,000 thermocycles in the present study; these results were similar to the results in other studies for the impact strength of a high-impact acrylic denture base resin after thermocycling 5,000 times ${ }^{11)}$ and for the impact strength of a conventional denture base resin after thermocycling 50,000 times ${ }^{22)}$. The reason is also most likely due to water sorption and static fatigue caused by thermal stress, as a result, these affected the impact strength of the two high-impact acrylic denture base resins.

In this study, the elastic moduli of the high-impact acrylic denture base resins increased and the impact strength decreased after long-term water immersion or thermal shock; therefore, they became stiff and brittle. These results indicated that long-term water immersion or thermal shock affected the mechanical properties of high-impact acrylic denture base resins. It is well known that water sorption alters the dimensions of denture base acrylic resins. Under the conditions of the present experiment, long-term water immersion or thermal shock did not change the flexural strength at the proportional limit and increased the elastic modulus of the high-impact acrylic denture base resins. A decrease in the impact strength of high-impact acrylic denture base resins results in brittleness, which is not acceptable clinically. However, no change in the flexural strength at the proportional limit of high-impact acrylic denture base resins means they maintain their resistance to plastic deformation and an increase in the elastic modulus of high-impact acrylic denture base resins causes stiffness, which are both clinically acceptable. Therefore, clinicians should be well aware of the mechanical properties of a high-impact acrylic denture base resin to be sure the denture delivered to each patient is suitable.

\section{CONCLUSIONS}

Under the conditions of the present experiment, the following conclusions may be drawn:

1. Long-term water immersion or thermal shock did not change the flexural strengths at the proportional limit of high-impact acrylic denture base resins.

2. The elastic moduli of high-impact acrylic denture base resins significantly increased after longterm water immersion or thermal shock.

3. Long-term water immersion or thermal shock significantly decreased the impact strengths of high-impact acrylic denture base resins.

\section{ACKNOWLEDGMENTS}

The authors would like to thank the GC Corporation for supplying some of the materials used in this project.

\section{REFERENCES}

1) Hargreaves AS. The prevalence of fractured dentures. A survey. Br Dent J 1969; 126: 451-455.

2) Yli-Urpo A, Lappalainen R, Huuskonen O. Frequency of damage to and need for repairs of removable dentures. Proc Finn Dent Soc 1985; 81: 151-155.

3) Polyzois GL, Andreopoulos AG, Lagouvardos PE. Acrylic resin denture repair with adhesive resin and metal wires: effects on strength parameters. J Prosthet Dent 1996; 75: 381-387.

4) Kim SH, Watts DC. The effect of reinforcement with woven E-glass fibers on the impact strength of complete dentures fabricated with high-impact acrylic resin. J Prosthet Dent 2004; 91: 274-280.

5) Powers JP, Sakaguchi RL editor. Craig's Restorative Dental Materials, 12th ed. St. Louis: Mosby; 2006. p. 514-526.

6) Rodford R. The development of high impact strength denturebase materials. J Dent 1986; 14: 214-217.

7) Polyzois GL, Karkazis HC, Zissis AJ, Demetriou PP. Dimensional stability of dentures processed in boilable acrylic resins: a comparative study. J Prosthet Dent 1987; 57: 639647.

8) Smith LT, Powers JM, Ladd D. Mechanical properties of new denture resins polymerized by visible light, heat, and microwave energy. Int J Prosthodont 1992; 5: 315-320.

9) Jagger D, Harrison A, Jagger R, Milward P. The effect of the addition of poly(methyl methacrylate) fibres on some properties of high strength heat-cured acrylic resin denture base material. J Oral Rehabil 2003; 30: 231-235.

10) Zappini G, Kammann A, Wachter W. Comparison of fracture tests of denture base materials. J Prosthet Dent 2003; 90: 578-585.

11) Machado AL, Puckett AD, Breeding LC, Wady AF, Vergani CE. Effect of thermocycling on the flexural and impact strength of urethane-based and high-impact denture base resins. Gerodontology 2012; 29: e318-323.

12) Takahashi Y, Kawaguchi M, Chai J. Flexural strength at the proportional limit of a denture base material relined with four different denture reline materials. Int J Prosthodont 1997; 10: 508-512.

13) Takahashi Y, Chai J, Kawaguchi M. Effect of water sorption on the resistance to plastic deformation of a denture base material relined with four different denture reline materials. Int J Prosthodont 1998; 11: 49-54.

14) Chai J, Takahashi Y, Kawaguchi M. The flexural strengths of denture base acrylic resins after relining with a visible-lightactivated material. Int J Prosthodont 1998; 11: 121-124.

15) Takahashi Y, Chai J, Kawaguchi M. Equilibrium strengths of denture polymers subjected to long-term water immersion. Int J Prosthodont 1999; 12: 348-352.

16) Takahashi Y, Chai J, Kawaguchi M. Strength of relined denture base polymers subjected to long-term water 
immersion. Int J Prosthodont 2000; 13: 205-208.

17) Phoenix RD. In: Anusavice KJ editor. Phillips' Science of Dental Materials. 11th ed. St. Louis: Sanders; 2003. p. 721757.

18) International Standard. ISO 20795-1 for Dentistry -Base polymers- Part1: Denture base polymers. Genève, Switzerland: International Organization for Standardization; 2008.

19) International Standard. ISO 1567 AMENDMENT 1 for Dentistry -Denture base polymers AMENDMENT 1. Genève, Switzerland: International Organization for Standardization; 2003.

20) International Standard. ISO 179-1 for Plastics
-Determination of Charpy impact properties- Part 1: Noninstrumented impact test. Genève, Switzerland: International Organization for Standardization; 2000.

21) Takahashi Y, Hamanaka I, Shimizu H. Flexural properties of denture base resins subjected to long-term water immersion. Acta Odontol Scand 2013; 71: 716-720.

22) Takahashi Y, Hamanaka I, Shimizu H. Effect of thermal shock on mechanical properties of injection-molded thermoplastic denture base resins. Acta Odontol Scand 2012; 70: 297-302.

23) Arima T, Murata H, Hamada T. The effects of cross-linking agents on the water sorption and solubility characteristics of denture base resin. J Oral Rehabil 1996; 23: 476-480. 